Western University Scholarship@Western

1980

\title{
Inequality in the Local Public Sector
}

Sam Bucovetsky

Follow this and additional works at: https://ir.lib.uwo.ca/economicsresrpt

Part of the Economics Commons

Citation of this paper:

Bucovetsky, Sam. "Inequality in the Local Public Sector." Department of Economics Research Reports, 8002. London, ON:

Department of Economics, University of Western Ontario (1980). 
ISSN : 0318-725X

ISBN : $0-7714-0158-2$

RESEARCH REPORT 8002

INEQUALITY IN THE LOCAL PUBLIC SECTOR

by

Sam Bucovetsky

January, 1980

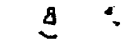


INEQUALITY IN THE LOCAL PUBLIC SECTOR*

\author{
Sam Bucovetsky \\ Department of Economics \\ University of Western Ontario \\ London N6A 5C2 Canada
}

\begin{abstract}
This paper examines the welfare economics of the levels of local public output in a metropolitan area. A fixed number of people of different income allocate themselves among different jurisdictions. It is shown that increases in per capita public output provision in the jurisdiction chosen by the rich residents will, in general, benefit poor residents of other jurisdictions. Some inequality in these public output levels (between jurisdictions) wi 11 maximize the "consumers ' surplus" measure of aggregate welfare.
\end{abstract}

\title{
January 1980
}

* This is a revised version of Chapter 2 of my thesis "Housing Markets and the Local Public Sector in a Metropolitan Area: A Theoretical Analysis". I wish to thank my committee, W. Bralnard (Chairman), J. Quigley and B. Wright for their advice. A Canada Council doctoral fellowship provided financial support for the thesis. 


\section{Introduction}

Equalization of the "quality" of public output provided by different local governments seems to be an idea whose time has come. ${ }^{1}$ Implementation of this idea has given rise to some disagreement. But the notion that increasing per capita local expenditure in jurisdictions currently spending relatively little will benefit that jurisdiction's residents seems widely accepted. 2 In this paper such a notion will be challenged.

From the outset it should be made clear that I am making some strong assumptions. The crucial one is that all residents are mobile. This means that residents of jurisdictions with low levels of public spending have chosen to live there. Raising that level will in a sense thwart the wishes of residents. If there are barriers to mobility (such as zoning restrictions in some jurisdictions), the conclusions of this paper may not be applicable. For then residents of low-spending towns may only be there because they are barred from moving to their preferred location. In such a situation the case for equalization of local public expenditure is clearly much stronger. But with perfect mobility, it will be shown that residents of lowspending jurisdictions will always benefit from increases in spending by higher-spending jurisdictions. In addition, increases in per capita expenditure by the low-spending jurisdiction eventually will make its residents worse off. These strong results hold for a 2 -jurlsdiction world in wh ich there is no substitution of land for other inputs in housing. They are weakened when these assumptions are modified. In particular, consideration of variable proportions in housing complicates the analysis considerably.

\section{The Basic Mode 1}

To begin with, consider some public output available at some level $z_{j}$ to all residents of jurisdiction $j$. This level will be treated as an 
exogenous parameter. Citizens do not get to vote, other than with their feet. The whole purpose of this paper is to examine the effects of changes in the parameter $z_{j}$ on the utility of various residents. There are $J$ jurisdictions. Each has a land area $\overline{\mathrm{L}}_{j}$ which is fixed. All land within the metropolitan area consisting of the $\mathrm{J}$ jurisdictions is identical. The metropolitan area also has a fixed population, which must be allocated to the various jurisdictions.

If the public output is a "good", as will be assumed, why would anyone choose to live in jurisdiction $j$, if jurisdiction $k$ provided more public output? One reason would be that jurisdiction $k$ levied higher income taxes on its residents. But this reason will be ruled out here. All jurisdictions are assumed to have two revenue sources: the local property tax and grants from a central government. These grants are treated as parametric by all residents. ${ }^{3}$ It remains possible that local property tax levels will affect mobility decisions. But a prospective renter does not directly pay the property tax. It only affects his/her decision through its effect on gross rents. Therefore what will, in this model, induce a citizen to choose the jurisdiction with low public output is a low level of rent.

It will be assumed that the prices of all goods and services, othe $r$ than housing, do not vary between jurisdictions. Neither will the income of an individual. The only variables affecting utility which vary between jurisdictions are the public output level $z_{j}$ and the unit price of housing $Q_{j} \cdot{ }^{4}$ Individuals $i$ are assumed to have utility functions of the form $U_{i}(x, h, z)$, where $x$ is a vector of consumption goods, $h$ is housing consumption, and $z$ the public output consumption. If the price of consumption goods (other than housing) is exogenous to the metroplitan area, and is denoted by $p$, then if the individual's income is $y_{1}$, his/her utility conditional on living in jurisdiction $\mathrm{j}$ can be written 
(1)

$$
V_{i}\left(y_{i}, Q_{j}, z_{j}\right)=\max _{x, h} U_{i}(x, h, z) \text { subject to } p \cdot x+Q_{j} h \leq y_{i}
$$

The individual's decision is then to find the jurisdiction $j$ which maximizes this mixed direct-indirect utility function $V_{i} \cdot$

The housing price $Q_{j}$ is endogenous, and its detemination will be explained below. In equilibrium, it certainly must be true that if $z_{j}>z_{k}$ then $Q_{j}>Q_{k}$. Otherwise no one will choose to live in jurisdiction $k$, if it had lower public output and higher housing prices than some other jurisdiction. Let the jurisdictions be numbered so that $z_{1}<z_{2}<\ldots,<z_{J}$. Therefore $Q_{1}<Q_{2}<\ldots,<Q_{J}$. Jurisdictions with a low index (and low level of $z_{j}$ ) will be referred to as "low service" jurisdictions.

Consider now an individual's indifference curves for $V_{1}$, with $Q$ on the vertical axis, and $z$ on the horizontal. Since $z$ is a good and $Q$ a bad, these slope up. Ellickson (1971) used these indifference curves to examine jurisdictional choices of different individuals in a model similar to this one. As can be seen in Figure 1, "high service" jurisdictions will be occupied by people with steep indifference curves. An immediate corollary of this, noted by Ellickson is that "high service" jurisdictions will be inhabited by wealthy residents if and only if the slope of these indifference curves, $-\left(\partial v_{i} / \partial z\right) /\left(\partial v_{i} / \partial Q\right)$ rises with wealth. I will refer to this case as "normal stratification".

One implication of normal stratification is that there is no need for minimum lot-size zoning in high-service jurisdictions. The low-income residents of the metropolitan area will choose low-service jurisdictions, because of their tastes, even if they are allowed to purchase small lots in high-service jurisdictions. Conditions which imply normal stratification, and some evidence indicating that they actual1y hold, are presented in Ellickson (1971), 
Figure 1

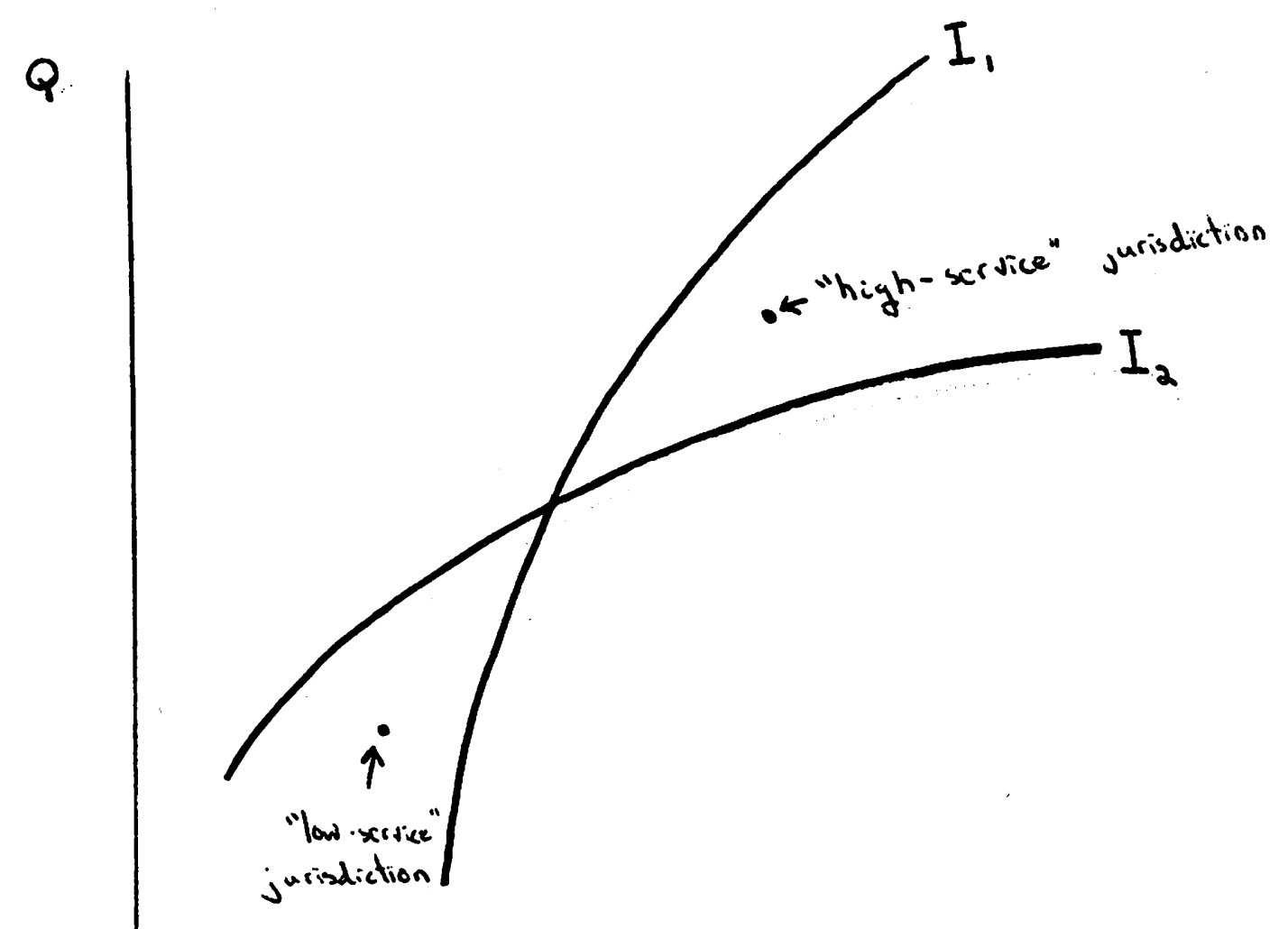


Bucovetsky (1979) and Burstein (1979). For much of the analysis here, such conditions are not necessary. All that is required is that there be some parameter $\mathrm{y}$ distributed over the population, so that higher values of $\mathrm{y}$ imply steeper indifference curves (through every point $(Q, z)$ ). This parameter measures the taste for the public output, relative to housing consumption. But for concreteness, it will be referred to as "income". On1y in the latter sections of the paper ${ }^{5}$ will this reference have any substance. Until then, a11 I require is that some sort of unambiguous parameterization of the slope of these indifference curves be possible.

Given the assumption that people with high values of $y$ will prefer high-service jurisdictions, it follows that in equilibrium there will be a set of "cut-off" levels $y_{j}$, such that people of income between $y_{j-1}$ and $y_{j}$ will prefer jurisdiction $j$, where $y_{0}<y_{1}<\ldots,<y_{J^{*}}$ Figure 2 illustrates this. If $\mathrm{y}$ does refer to income, each jurisdiction contalns a stratum of the income distribution, with higher levels of public output associated with higher income. There are also two other types of equilibrium conditions which must be satisfied. Each jurisdiction's land market must clear. And each jurisdiction's public sector revenues must equal public sector expenditures. Elsewhere I have shown that such an equilibrium exists, if one is willing to accept fractional allocations of people to jurisdictions. 6

There are three types of endogenous variables corresponding to these equilibrium conditions. First are the "cut-off" income levels described above. Second are the land prices in each jurisdiction. Although land in each jurisdiction is physically identical, in general its price should vary between jurisdictions. That is because renting a house in a jurisdiction is in effect renting a joint product, the house itself plus the local public output in that jurisdiction. The third type of endogenous variable is the property tax rate in each jurisdiction. 
6

Figure 2

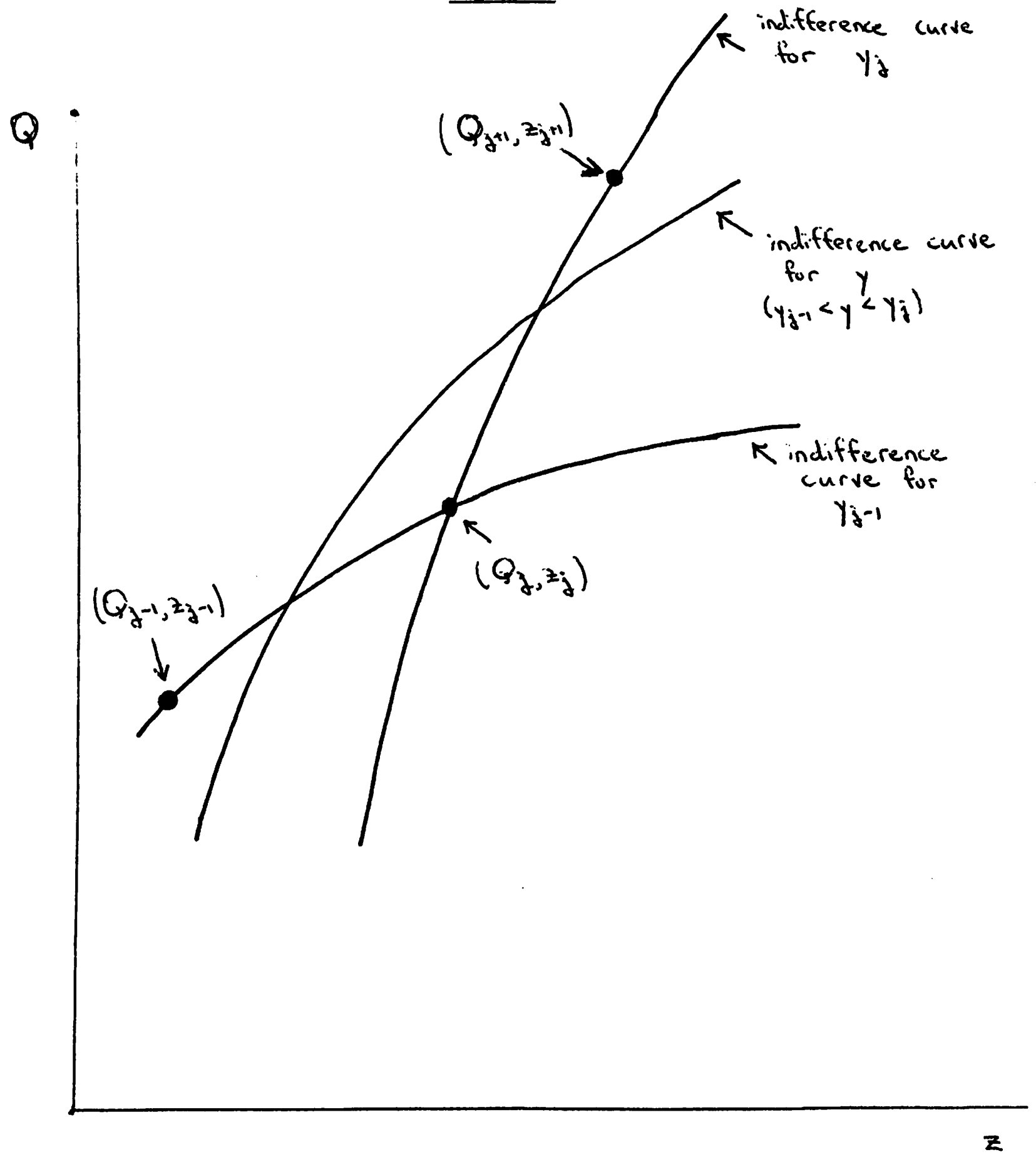


Let $r_{j}$ denote the annual rent on land in jurisdiction $j$. It is assumed that housing is produced from land and other inputs by a constantreturns-to-scale production function. This does not rule out the case of fixed coefficients, which will occupy much of the paper. Other inputs are available in perfectly elastic supply, at a price of 1 . Let $g(l, k)$ be the production function for housing, where $\ell$ is land input and $k$ the other input. Then in jurisdiction $j$, cost-minimizing housing producers choose a landhousing ratio $\gamma\left(r_{j}\right)$, and an other-input-housing ratio $\mu(r)$ to minimize unit costs $r_{j} \gamma\left(r_{j}\right)+\mu\left(r_{j}\right)$ subject to $g(\gamma, \mu)=1$. Since the property tax is assumed to be levied as a fraction of the housing price, it does not enter in this factor-intensity decision. Denote these minimum unit costs by $q\left(r_{j}\right)$. By definition

$$
q(r)=r \gamma(r)+\mu(r)
$$

Clearly the land-housing ratio $\gamma$ is non-increasing in $r_{j}$ and the cost $q$ increases with the land price. It follows as an envelope relation ${ }^{7}$ that

$$
q^{\prime}(r)=\gamma(r)
$$

The property tax rate $t_{j}$ is assumed to be a proportion of the netof-tax annual housing price. Competition among housing suppliers ensures that the annual gross unit price of housing $Q_{j}$ satisfies

$$
Q_{j}=\left(1+t_{j}\right) q\left(r_{j}\right)
$$

The total tax base in jurisdiction $j$ is the value of housing there. Since $\bar{L}_{j}$ is the land area there, and $\gamma\left(r_{j}\right)$ the land-housing ratio for all housing in the jurisdiction, total tax collections can be written $t_{j} q\left(r_{j}\right) \bar{L}_{j} / \gamma\left(r_{j}\right)$. It is assumed that the public output has a "pure private good" technology. 
That is, the total cost of providing public output level $\mathbf{z}_{\mathbf{j}}$ to population $P_{j}$ is proportional to the population. This assumption is in accordance with most empirical work on cost functions for the local public sector. 8 By appropriate choice of unit, this total cost can be written $z_{j} P_{j}$.

For convenience, the population will be represented as a continuum. The density function $f(y)$ will represent the distribution of the characteristic y. This function is assumed continuous, and positive-valued over some interval $\left(y_{0}, y_{1}\right)$. The population of jurisdiction $j$ is then $\int_{y_{j-1}}^{y_{j}} f(y) d y$. Let the demand for housing be denoted $h(y, Q)$. Since the public output level $z_{j}$ does not appear as an argument, the level of output has been assumed not to affect the choice between housing and other private goods. This greatly simplifies the analysis, and seems a reasonable first approximation. Before proceeding, it should be noted that the characteristic $y$ is being treated here as having an exogenously given distribution. If $y$ is income, then this would not be true if anyone owned land in the metropolitan area. Then income would depend on the land prices $r_{j}$. What now must be made explicit is that it is assumed that all land is owned by non-residents. In the first results to be presented, the welfare of these land owners will be neglected. Residents in effect use the public sector to exploit these outsiders. However, subsequently the welfare of these land owners will be included in an aggregate welfare measure. The assumption of absentee land ownership is made purely for analytic simplicity. Otherwise the demand functions for housing would change with land prices, and consideration of how land holdings varied with income would be required.

Given the definitions presented, the 3J-1 equilibrium conditions which define the $3 \mathrm{~J}-1$ endogenous variables can be written as equations (5)-(7) below. Equation (5) defines the "cut-off" levels $y_{j}(1 \leq j \leq J-1)$ as being those where 
the individual is indifferent between jurisdictions $j$ and $j+1$. Equation (6) is the market-clearing condition for land in jurisdiction $j$. Equation (7) is the local budget constraint. Here $s_{j}$ is per-capita aid from the central government, which is regarded as exogenous.

$$
V\left(y_{j}, Q_{j}, z_{j}\right)=V\left(y_{j}, Q_{j+1}, z_{j+1}\right) \quad j=1,2, \ldots, J-1
$$

$$
\begin{aligned}
& \bar{L}_{j}=\gamma\left(r_{j}\right) \int_{y_{j-1}}^{y} h\left(y, Q_{j}\right) f(y) d y \quad j=1,2, \ldots, J \\
& \left(z_{j}-s_{j}\right) \int_{y}^{y} y_{j-1} f(y) d y=t_{j} q\left(r_{j}\right) \bar{L}_{j} / \gamma\left(r_{j}\right) \quad j=1, \ldots, J
\end{aligned}
$$

The only link between jurisdictions is through equation (5). A change in public output in jurisdiction $\mathrm{k}$ will only affect variables in some other jurisdiction $j$ by altering the cut-off levels $y_{j-1}$ and $y_{j}$. This characteristic of the equilibrium conditions will be used in analyzing the effects of public output changes.

\section{Fixed Coefficients in Housing Production}

Suppose now that there are fixed coefficients in housing production, so that $\gamma$ does not vary with $r$. Then examination of equation (6) shows that the gross rent $Q_{j}$ is determined only by the population cut-off levels $y_{j-1}$ and $y_{j} \cdot$ Next, suppose there are only two jurisdictions. Then there is only one endogenous cut-off level ( $y_{0}$ is the minimum of the exogenous income distribution, $\mathrm{y}_{2}$ the maximum). It then follows

Observation: With fixed coefficients in housing, and only two jurisdictions, both of the jurisdictions' housing prices, $Q_{1}$ and $Q_{2}$ are determined solely by the identity of the marginal resident, $\mathrm{y}_{1}$. 
If the cut-of: income level rises, population rises in the low-service jurisdiction, and falls in the high-service jurisdiction. This must raise $Q_{1}$ and lower $Q_{2}$. With fixed coefficients in housing, it must be true that any increase in public output $z_{2}$ in the high-service jurisdiction will lower $y_{1}$. Suppose to the contrary that $y_{1}$ did not fall. This means $Q_{1}$, the gross rent in the low-service jurisdiction, does not fall. The utility of the previously marsinal resident, conditional on living in the low-service jurisdiction, $V\left(y_{1}, Q_{1}, z_{1}\right)$ therefore is the same or lower than before the change $\left(z_{1}\right.$ has not changed). If $y_{1}$ is constant or has increased, then $Q_{2}$ cannot have risen. And $z_{2}$ has increased. Thus the previously marginal resident's utility in the high-service jurisdiction $V\left(y_{1}, Q_{2}, z_{2}\right)$ must have increased. Since he/she was previously indifferent, now jurisdiction 2 is preferred. Thus there is migration into the high-service jurisdiction. Hence the original assumption is false. Analogous reasoning establishes that $\partial y_{1} / \partial z_{1}>0$. These results can be summarized:

Proposition: With 2 jurisdictions, and fixed coefficients in housing, an increase in public output in the high service (low-service) jurisdiction, must lower (raise) the cut-off income level $y_{1}$, raising (lowering) $Q_{2}$ the rent in the high-service jurisdiction, and lowering (raising) $Q_{1}$.

It immediately follows that any increase in public expenditure per capita by the high-service jurisdiction must increase the welfare of all residents of the low-service jurisdiction. Their public output consumption is unchanged, and their rent has fallen. But it is also true that everyone's welfare increases in the high-service jurisdiction. The new marginal resident's utility must have increased. He/she could have stayed in jurisdiction 1 , and increased utility due to the lower rent. Since he/she chose to move to jurisdiction 2 , utility there must have increased further. This change in utility can be written 


$$
\Delta V\left(y_{1}, Q_{2}, z_{2}\right)=\frac{\partial V}{\partial Q}\left(\frac{\partial Q_{2}}{\partial z_{2}}\right)+\frac{\partial V}{\partial z_{2}}>0
$$

Since $\frac{\partial V}{\partial Q}<0, \frac{\partial Q_{2}}{\partial z_{2}}>0$ and $\frac{\partial V}{\partial z_{2}}>0$, the first term is negative and the second is positive. The fact that the resident has chosen jurisdiction 2 indicates the positive effect of higher output outweighs the negative effect of higher rent.

It will be recalled that higher values of $\mathrm{y}$ mean steeper indifference curves for $\mathrm{V}$. Therefore an infra-marginal resident of the high-service jurisdiction has $\mathrm{y}>\mathrm{y}_{1}$, and steeper indifference curves. By definition, this implies he/she has a higher value for $-(\partial v / \partial z) /(\partial v / \partial Q)$. But from equation (8), this implies that his/her utility must also have increased after the changes. Therefore all renters in the metropolitan area are made better off by the increase in public output in the high-service jurisdiction. But the analogous result does not necessarily follow for increaes in public output in the low-service jurisdiction. As before the marginal resident must be better off. But now the infra-marginal residents in the output-increasing jurisdiction have shallower indifference curves. Compared to the marginal resident, they value the public output increase less relative to the rent increase. That is why they have chosen the low-service jurisdiction. Arbitrary public output increases in their jurisdiction may well make them worse off.

Theorem 1: Any increase in public output in the high service jurisdiction must make all renters better off, in the two-jurisdiction, fixed-coefficient metropolitan area. Increases in public output in the low service jurisdiction make renters in high service jurisdiction better off, but may lower the utility of those with a low taste for the public output (low y). 
Note that the interpretation of the characteristic y as "income" was not needed in this result. Also note that all the changes in public output discussed here must preserve the inequality $z_{2} \geq z_{1}$. If this inequality were reversed, there would be mass migration, as the jurisdictions traded populations. Since the land areas of the jurisdiction need not be equal, there is no presumption that this switch would be symmetric. The issue of the optimal ordering of jurisdictions will not be addressed in this paper.

If there are more than two jurisdictions, but still fixed coefficients in housing, a weaker version of the above theorem holds. In this situation rent in jurisdiction $j$ depends on the two cut-off levels $y_{j-1}$ and $y_{j} \cdot$ If public output $z_{j}$ increases in one jurisdiction, two results are possible. It may be that everyone is made better off. In this case $y_{j}, y_{j+1}, \ldots, y_{J-1}$ all increase, in such a way as to lower rents in jurisdictions $\mathrm{j}+1$ through $\mathrm{J}$. The cut-off levels $y_{1}, \ldots, y_{j-1}$ all decrease, in such a way to lower rents in jurisdictions 1 through $j-1$. Rent increases in jurisdiction $j$, but all residents are still better off because of the increased public output. In the other case, the situation in jurisdictions $j+1$ through $J$ is the same. Rents all decrease, and $y_{j}$ through $y_{J-1}$ all increase. But now $y_{1}, y_{2}, \ldots, y_{j-1}$ all increase as well. Rents increase in jurisdictions 1 through $j-1$. All residents of these jurisdictions are made worse off. The residents of jurisdiction $j$ who have low values of $y$ are made worse off, and those with a high value of $j$ are made better off. But if $j=J$, only the first result can occur. As in the 2-jurisdiction metropolitan area, all renters are made better off by increases in public output in the highest service jurisdiction. The above results, summarized below, are proved in analogous manner to the 2-jurisdiction theorem. The proof is deferred to an appendix. 
Theorem 2: If jurisdiction $j$ raises public output, with fixed coefficients in housing, there is some income $\hat{y}$ such that welfare increases for all (and only) people with $y_{.}>\hat{y}$. Either $\hat{y}=y_{0}$, or $y_{j-1}<\hat{y}<y_{j}$. If $j=J, \hat{y}=y_{0}$, so that all renters benefit.

IV. Acknowledging Land Owners' Welfare

Returning to a world of two jurisdictions, which will occupy the remainder of this paper, it is clear that land owners bear the tax burden when there are fixed coefficients. This follows from the observation that rents are demand-determined. Also, it did not matter above whether any increases in public output were financed from property tax revenue or from central government grants. If an increase in public output in the low-service jurisdiction lowers utility of some residents, as may occur, this can happen even if the increase is financed by a gift from outside.

But although land owners bear the tax burden, it is not necessarily true that public output increases must make them worse off. Suppose that the price elasticity of housing demand is a constant $-\eta$. If jurisdiction 2 increases per capita public output, all the effect in jurisdiction 1 is through the cut-off level. Differentiating equation (6)

$$
\frac{\partial Q_{1}}{\partial y_{1}}=\frac{f\left(y_{1}\right)}{\eta} \frac{Q_{1}}{\bar{E}_{1}} \gamma h\left(y_{1}, Q_{1}\right)>0
$$

From equation (7)

$$
\left(z_{1}-s_{1}\right) f\left(y_{1}\right)=\frac{\partial t_{1}}{\partial y_{1}} \frac{q_{1} \bar{L}_{1}}{\gamma\left(r_{1}\right)}+\frac{\partial r_{1}}{\partial y_{1}} t_{1} \bar{L}_{1}
$$

Since by definition $Q_{1}=\left(1+t_{1}\right)\left(q\left(r_{1}\right)\right)$ then 


$$
\frac{\partial t_{1}}{\partial y_{1}} q_{1}+\gamma\left(r_{1}\right)\left(1+t_{1}\right) \frac{\partial r_{1}}{\partial y_{1}}=\frac{\partial Q_{1}}{\partial y_{1}}
$$

so that

$$
\frac{\partial \mathrm{r}_{1}}{\partial \mathrm{y}_{1}}=\frac{\mathrm{f}\left(\mathrm{y}_{1}\right)}{\overline{\mathrm{L}}_{1}}\left[\frac{\mathrm{h}\left(\mathrm{y}_{1}, \mathrm{Q}_{1}\right) \mathrm{Q}_{1}}{\eta}-\left(\mathrm{z}_{1}-\mathrm{s}_{1}\right)\right]
$$

If housing demand is sufficiently elastic, an increase in population in the low service jurisdiction will lower land prices. But closer examination reveals this to be unlikely. Here, for the first time, the characteristic $y$ must be interpreted as income. If $\mathrm{y}$ is income and housing is a normal good, the average housing consumption $\bar{h}$, in the low service jurisdiction must be less than the housing consumed by the richest resident, $h\left(y_{1}, Q_{1}\right)$. Local budget balance requires that average per capita tax revenues $t_{1} q_{1} \bar{h}_{1}$ equal net expenditure per capita $\left(z_{1}-s_{1}\right)$. Therefore from (12), a necessary condition for $\frac{\partial r_{1}}{\partial y_{1}}$ to be negative is $t_{1} q_{1}>\frac{Q_{1}}{\eta}$. This condition is equivalent to $n>1+\frac{1}{5}$, which seems to require an implausibly high price elasticity of housing demand. Therefore, the reasonable result that an increase in population in jurisdiction 1 raises net land prices there should hold. This result is less likely in jurisdiction 2, since there the quantity of housing consumed by the marginal resident $h\left(y_{1}, Q_{2}\right)$ is less than the average. The addition of new residents is more likely to lower property values, since new residents bring in a negative fiscal residual. This tends to raise taxes, and lower land values, and may exceed the direct effect on land prices of increased gross housing prices.

However, if the cause of the migration is an increase in public output in the high service jurisdiction, this increase in output will affect land prices directly, quite apart from the effects of induced immigration. 
This direct effect must be to decrease land prices. If population is held constant, so must the gross housing price $Q_{j}$. By definition, $Q_{j}=q\left(r_{j}\right)+t_{j} q\left(r_{j}\right)$. With the land-housing ratio $\gamma$ and population constant, equation (7) shows an increase in $z_{2}$ must therefore increase $t_{j} q\left(r_{j}\right)$. With $Q_{j}$ constant, $q$ and thus $r_{j}$ must fall. Thus the overall effect of a public output increase in the high-service jurisdiction on land prices there has 2 components. The direct effect must be to lower land prices. The indirect effect, through immigration, is ambiguous. The case cannot be ruled out that the indirect effect is positive and outweighs the direct effect. But it is more plausible that land prices decline in both jurisdictions after the public output increase, supporting the notion that renters use the public sector to exploit absentee land owners.

If the renters' welfare is considered, it is clearly optimal to raise public output in the high service jurisdiction as much as possible. This upper limit presumably will be reached when land values there reach zero. There is some conflict with regard to public policy in the low service jurisdiction. Those residents with a high taste for the output (high income, if normal stratification holds) will want arbitrarily large increases in public output there as well. But lower-income residents will eventually lose as public output increases, and will thus desire some finite maximum public output level.

Suppose now the welfare of land owners is explicitly considered. In particular, assume that responsibility for an equitable income distribution rests with the central government. Then an aggregate measure of welfare can be obtained by summing benefits across three groups: renters, land owners, and the taxpayers who pay the subsidies $s_{1}$ and $s_{2}$. Land owners' total welfare is just their income $r_{1} \bar{L}_{1}+r_{2} \bar{L}_{2}$. Taxpayers' costs are 
$s_{1} P_{1}+s_{2} P_{2}$, where $P_{i}$ is the population of jurisdiction $i$. The utility of a typical renter is $V(y, Q, z)$. If rents and/or public output change, the measure of the value (in dollars) of the change in his/her utility is $\left(\frac{\partial V}{\partial Q} \Delta Q+\frac{\partial V}{\partial z} \Delta z\right) / \lambda$, where $\lambda$ is the marginal utility of income. From Roy's Identity, $\frac{\partial V}{\partial Q} / \lambda=-h(y, Q)$ and $\frac{\partial V}{\partial z} / \lambda=\phi(y, Q, z)$, where $\phi$ is the marginal rate of substitution of the public output for the numéraire.

Consider now the effect of a public output increase in the high-service jurisdiction on renters' welfare in the low-service jurisdiction. This equals $-\int_{y_{0}}^{y_{1}} h(y, Q) \Delta Q_{1} f(y) d y$, where $\Delta Q_{1}$ is the induced change in housing rents (due to decreased population). This equals $-\frac{\bar{L}_{1}}{\gamma} \Delta Q_{1}$. Equations (10) and (11) imply

$$
\frac{\overline{\mathrm{L}}_{1}}{\gamma} \frac{\partial \mathrm{Q}_{1}}{\partial \mathrm{y}_{1}}-\overline{\mathrm{L}}_{1} \frac{\partial \mathrm{r}_{1}}{\partial \mathrm{y}_{1}}=\left(\mathrm{z}_{1}-\mathrm{s}_{1}\right) \mathrm{f}\left(\mathrm{y}_{1}\right)
$$

The change in taxpayers' costs due to the emigration induced is $s_{1} f\left(y_{1}\right) \Delta y_{1}$. Therefore, (13) implies that the total change in aggregate welfare due to changes caused in the low-service jurisdiction can be written

$$
\Delta \mathrm{w}_{1}=-\mathrm{z}_{1} \mathrm{f}\left(\mathrm{y}_{1}\right) \quad \Delta \mathrm{y}_{1}
$$

In the high-service jurisdiction, where public output has changed, the welfare changes have two components. The first, due to immigration, is similar to that in low service jurisdictions. The sum of renters' gain $-\left(\int_{y_{1}}^{y_{2}} h\left(y, Q_{2}\right) \frac{\partial Q_{2}}{\partial y_{1}} f(y) d y\right) \Delta y_{1}$ and land owners' gain $\overline{\mathrm{L}}_{2} \frac{\partial \mathrm{r}_{2}}{\partial y_{1}} \Delta y_{1}$ and taxpayers' gain $-s_{2} f\left(y_{1}\right) \quad \Delta y_{1}$ is $z_{2} f\left(y_{1}\right) \Delta y_{1}$. The direct effect of public output increases 
on renters is $\int_{y_{1}}^{y_{2}}\left[\phi\left(y, Q_{2}, z_{2}\right) \Delta z_{2}-h\left(y, Q_{2}\right) \Delta Q_{2}\right] f(y) d y$ and on land owners is $\mathrm{L}_{2} \frac{\partial \mathrm{r}_{2}}{\partial \mathrm{z}_{2}} \Delta \mathrm{z}_{2}$

$$
\text { Since } t_{q}=Q-q \text {, differentiation of equation (7) yields }
$$

$$
\mathrm{P}_{2}=\frac{\overline{\mathrm{L}}_{2}}{\gamma} \frac{\partial \mathrm{Q}_{2}}{\partial \mathrm{z}_{2}}-\overline{\mathrm{I}}_{2} \frac{\partial \mathrm{r}_{2}}{\partial \mathrm{z}_{2}}
$$

(where $\frac{\partial Q_{2}}{\partial z_{2}}, \frac{\partial r_{2}}{\partial z_{2}}$ refer to the direct effects of $z_{2}$, excluding induced effects through immigration). This means the total direct effect on welfare is

$\int_{y_{1}}^{y_{2}} \phi\left(y, Q_{2}, z_{2}\right) f(y) d y-P_{2}$. Since the cost of the public output is $P_{2} z_{2}, P_{2}$ is the aggregate marginal rate of transformation. Thus the total direct effect can be written IMRS - MRT. ${ }^{9}$ Combining all the terms, the overall net benefit of a marginal increase in public output in the high-service jurisdiction is

$$
\frac{\partial W}{\partial z_{2}}=f\left(y_{1}\right)\left(z_{2}-z_{1}\right) \frac{\partial y_{1}}{\partial z_{2}}+\left(\Sigma M R S_{2}-M^{-T T_{2}}\right)
$$

Similarly, the effect of an increase in public output in the low-service jurisdiction is

$$
\frac{\partial W}{\partial z_{1}}=f\left(y_{1}\right)\left(z_{2}-z_{1}\right) \frac{\partial y_{1}}{\partial z_{1}}+\left(\Sigma M S_{1}-M T_{1}\right)
$$

Since it has already been established that $\frac{\partial y_{1}}{\partial z_{2}}<0$ and $\frac{\partial y_{1}}{\partial z_{1}}>0$, the levels of public output which maximize $W$, the "consumers' surplus" measure of total welfare must satisfy

Theorem 3: With fixed coefficients in housing production, and 2 jurisdiction, the "conventional" measure ( $\mathrm{M} R \mathrm{R}$ - MRT) of benefits of public expenditure over-values those benefits in the high-service jurisdiction and under-values them in the low-service jurisdiction. At the public output levels which 
maximize $W$ there will be an over-supply in the conventional sense (MRT $>$ EMRS) in the low-service jurisdiction and an under-supply in the high service jurisdiction.

However, the above assertion depended on the normalization that jurisdiction 2 was the high-service jurisdiction. As mentioned above, since it is not required that $\overline{\mathrm{L}}_{1}=\overline{\mathrm{L}}_{2}$, a "reversal of roles" of the 2 jurisdictions may have substantive effects. What will be shown next is that, whatever jurisdiction is assigned the high-service role, there will be an optimum of $W$ with some variance in public output. That is, the $\left(z_{1}, z_{2}\right)$ which maximize $W$ subject to $z_{2} \geq z_{1}$ will involve $z_{2}>z_{1}$. And the $\left(z_{1}, z_{2}\right)$ which maximize $W$ subject to $z_{2} \leq z_{1}$ will involve $z_{2}<z_{1}$. The overall optimum is thus one of these 2 choices. First, what would happen if we had an equilibrium with equal public output $z_{1}=z_{2}$ ? Clearly, then, in equilibrium $Q_{1}=Q_{2}$. Since all renters are indifferent between jurisdictions, normal stratification need not occur. Any allocation of the population of the metropolitan area to the two jurisdictions such that (i) both land markets clear (ii) both local budgets balance (iii) the housing price is the same will be an equilibrium. Total welfare from any such allocation is

$$
W=r_{1} \bar{L}_{1}+r_{2} \bar{L}_{2}+\int_{y_{1}}^{y_{2}} v(y, Q, z) f(y) d y-s_{1} P_{1}-s_{2} P_{2}
$$

If a small shift is made in allocation (remaining in equilibrium), the change in welfare is

$$
\Delta \mathrm{W}=\overline{\mathrm{L}}_{1}\left(\Delta \mathrm{r}_{1}\right)+\overline{\mathrm{L}}_{2}\left(\Delta \mathrm{r}_{2}\right)-\Delta \mathrm{Q}\left(\frac{\overline{\mathrm{L}}_{1}}{\gamma}+\frac{\overline{\mathrm{L}}_{2}}{\gamma}\right)-\mathrm{s}_{1} \Delta \mathrm{P}_{1}-s_{2} \Delta \mathrm{P}_{2}
$$

(where the equilibrium condition $Q_{1}=Q_{2}$ has been used). But since $Q=t_{i} q_{i}+q_{i}$, 
$(i=1,2)$ therefore $\bar{L}_{i}\left(\Delta r_{i}-\frac{\Delta Q}{\gamma}\right)=-\frac{\bar{L}_{i}}{\gamma}\left(\Delta\left(t_{i} q_{i}\right)\right)$. Since $t_{i} q_{i} \frac{\bar{L}_{i}}{\gamma}=\left(z_{i}-s_{i}\right) P_{i}$,

$-\left(\Delta t_{i} q_{i}\right) \frac{L_{i}}{\gamma}=-\left(z_{i}-s_{i}\right) \Delta P_{i}$. So the overall effect on welfare of the change is

$-z_{1} \Delta P_{1}-z_{2} \Delta P_{2}$, which equals zero (since $z_{1}=z_{2}$, and $P_{1}+P_{2}$ is constant).

Therefore

Lemma: Any equilibrium allocation of population to jurisdictions with identical given public output $\left(z_{1}=z_{2}\right)$ yields identical total benefits.

Because of this result, attention can be restricted to segregated equilibria. If an equilibrium with $z_{1}=z_{2}$, and everyone of income less than (more than) $y_{1}$ living in jurisdiction 1 (2) (for some $y_{1}$ ) can be shown inferior to one with $z_{2}>z_{1}$, then so must every equilibrium with $z_{1}=z_{2}$. This segregated equilibrium can be defined as the 1 imiting case as $z_{2}$ approaches $z_{1}$ from above.

Suppose we have an equilibrium with $z_{2}=z_{1}$, and the rich living in jurisdiction 2. If $\frac{\partial w}{\partial z_{1}}<0$, welfare can be improved by lowering $z_{1}$, which would be feasible given the constraint $z_{1} \leq z_{2}$. If $\frac{\partial W}{\partial z_{1}} \geq 0$, then (from equation (17)), $\Sigma M^{2} S_{1}>$ MRT. But the public output level is the same in both jurisdictions. So is the housing price $Q$. Therefore people in jurisdiction must have higher marginal rates of substitution, since their income is higher. 10 Since the average MRS $\bar{\phi}_{i}$ must be higher in jurisdiction $2, \frac{\partial W}{\partial z_{2}}>0$. Therefore total welfare can be increased by increasing $z_{2}$. What has been shown is that for any equilibrium with $z_{2}=z_{1}$, and the rich segregated in jurisdiction 2 , there is some feasible policy (i.e., one with $z_{2}>z_{1}$ ) which increases welfare. An analogous result can be proved for $z_{1} \geq z_{2}$, with the rich living in jurisdiction 1. Combining these, and using the above lemma: 
Theorem 4: With fixed coefficients in housing production, normal stratification and some income inequality, maximization of "consumers' surplus" requires inequality of public output per capita across jurisdictions.

\section{Variable Coefficients in Housing Production}

The remainder of this paper is concerned with the case of variable coefficients in housing production. In this case, housing prices are no longer determined solely by demand, as can be seen from equation (6), where $\gamma$ is no longer constant. In this situation land owners can pass on some of the property tax burden to renters. (The assumption of a perfectly elastic supply curve for "other inputs" to housing means that my model gives the traditional, "pre-Mieszkowski" view of property tax incidence. See Edgeworth (1959) or Richman (1967)). Also there is now an excess burden to the property tax. By taxing "other inputs" more than the numeraire, the tax acts as an excise tax (on other inputs to housing). Therefore, welfare effects of public output changes will now involve terms representing changes in the excess burden of the property tax these changes induce.

The added complications caused by variable proportions mean that the remaining results will be ambiguous. Since housing prices are no longer demand-determined, the effects of an increase in population on them, $\frac{\partial Q_{1}}{\partial y_{1}}$ must be obtained from an application of Cramer's rule to equations (6) and (7). Let $\eta$ be the absolute value of the price elasticity of housing demand, which will be assumed constant. Define the term $\Delta_{1}$ by

$$
\Delta_{1}=-\frac{q\left(r_{1}\right) \bar{L}_{1}}{\gamma(r)} \int_{y_{0}}^{y_{1}}\left[\gamma^{2}\left(r_{1}\right) \frac{\eta}{Q_{1}}-\gamma^{\prime}\left(r_{1}\right)+\gamma^{\prime}\left(r_{1}\right) \eta \frac{t_{1}}{1+t_{1}}\right] h\left(y, Q_{1}\right) f(y) d y
$$


Then

$$
\begin{gathered}
\frac{\partial Q_{1}}{\partial y_{1}=\frac{f\left(y_{1}\right) q\left(r_{1}\right)}{\Delta_{1}}} \bar{L}_{1}\left\{-\gamma\left(r_{1}\right) h\left(y_{1}, Q_{1}\right)+\frac{\gamma^{\prime}\left(r_{1}\right)}{\gamma\left(r_{1}\right)}\left(z_{1}-s_{1}\right)\right. \\
\left.-\frac{\gamma^{\prime}\left(r_{1}\right)}{\gamma\left(r_{1}\right)} q\left(r_{1}\right) h\left(y_{1}, Q_{1}\right) t_{1}\right\}
\end{gathered}
$$

From (20), a sufficient condition for $\Delta_{1}$ to be negative is

$$
\eta<1+\frac{1}{t_{i}}
$$

which, as discussed earlier, seems a plausible restriction on the demand elasticity, and will be assumed to hold.

Given this assumption, the gross housing price will rise with population (as was the case with fixed coefficients) if the expression in brace brackets is negative. If substitution in housing is sufficiently elastic, this may not occur. Then any increase in the land price $r$ would greatly increase the capital-intensity of housing. With a fixed land area, this increases the total tax base. Hence the tax revenue per unit of housing, tq, will fall. With a high enough elasticity of substitution, the decrease in $\mathrm{tq}$ may be larger than the increase in $\mathrm{q}$ caused by a population influx. Then $Q_{1}$ may fall if $y_{1}$ rises.

To see conditions under which this perverse result can be excluded, note that the first 2 terms in the brace brackets in (21) are negative, while the last is positive. If the first term is larger than the last in absolute value, then, $\frac{\partial Q_{1}}{\partial y_{1}}>0$. If $\sigma$ is defined as the (absolute value of the) elasticity of substitution in housing production, then

(23) $\frac{\gamma^{\prime}(r)}{\gamma(r)}=-\left(\frac{q(r)-r \gamma(r)}{q(r)}\right) \frac{\sigma}{r}$ 
The expression in parentheses is the share of non-land inputs in housing costs. From (23), the first term in (21) will dominate the third if

$$
t_{1} \sigma \leq \frac{r_{1} \gamma\left(r_{1}\right)}{q\left(r_{1}\right)-r_{1} \gamma\left(r_{1}\right)}
$$

High values for both the tax rate $t$ and the elasticity of substitution $\sigma$ are required for the perverse result $\frac{\partial Q_{1}}{\partial y_{1}} \leq 0$ to hold. The right-hand side of (24) is land's share of housing cost. It should also be recalled that the tax rate $t$ is expressed as a fraction of annual, net-of-tax housing costs. It is thus much higher than the property tax as a proportion of housing value. ${ }^{11}$ Table 1 shows the values of $t_{1}, \sigma$, and $\frac{r \gamma}{q-r \gamma}$ for which (24) holds with equality. Lower values of $t$ or $\sigma$, or higher values of $\frac{r y}{q-r \gamma}$ than those in the table will satisfy (24). Equation (24) is sufficient, but not necessary for $\frac{\partial Q_{1}}{\partial y_{1}}$ to be positive. The second (positive) term in equation (21) will dominate the third if $z_{1}-s_{1}>q_{1} t_{1} h\left(y_{1}, Q_{1}\right)$. Since $z_{1}-s_{1}$ is the per capita cost (net of federal grants) of the local public sector, it must equal average tax revenue per capita. But since housing is a normal good, $q_{1} t_{1} h\left(y_{1}, Q_{1}\right)>q_{1} t_{1} \bar{h}_{1}$, so that the required inequality can never hold in jurisdiction 1 . However, if the mean income in jurisdiction 1 and the maximal income $y_{1}$ were close, then $\frac{\partial Q_{1}}{\partial y_{1}}$ could be positive even if inequality (24) did not hold. In the high-service jurisdiction, a similar expression for $\frac{\partial Q_{2}}{\partial y_{1}}$ can be derived. However here the marginal resident is poorer than average. The second term dominates the third, and $\frac{\partial Q_{2}}{\partial y_{1}}$ must be negative, regardless of the elasticity of substitution in housing . 
Table I

$$
\text { Value of } t \text { (for given } \sigma, \frac{r \gamma}{q-r \gamma} \text { ) such that }
$$

$$
\sigma t=\frac{r \gamma}{q-r \gamma}
$$

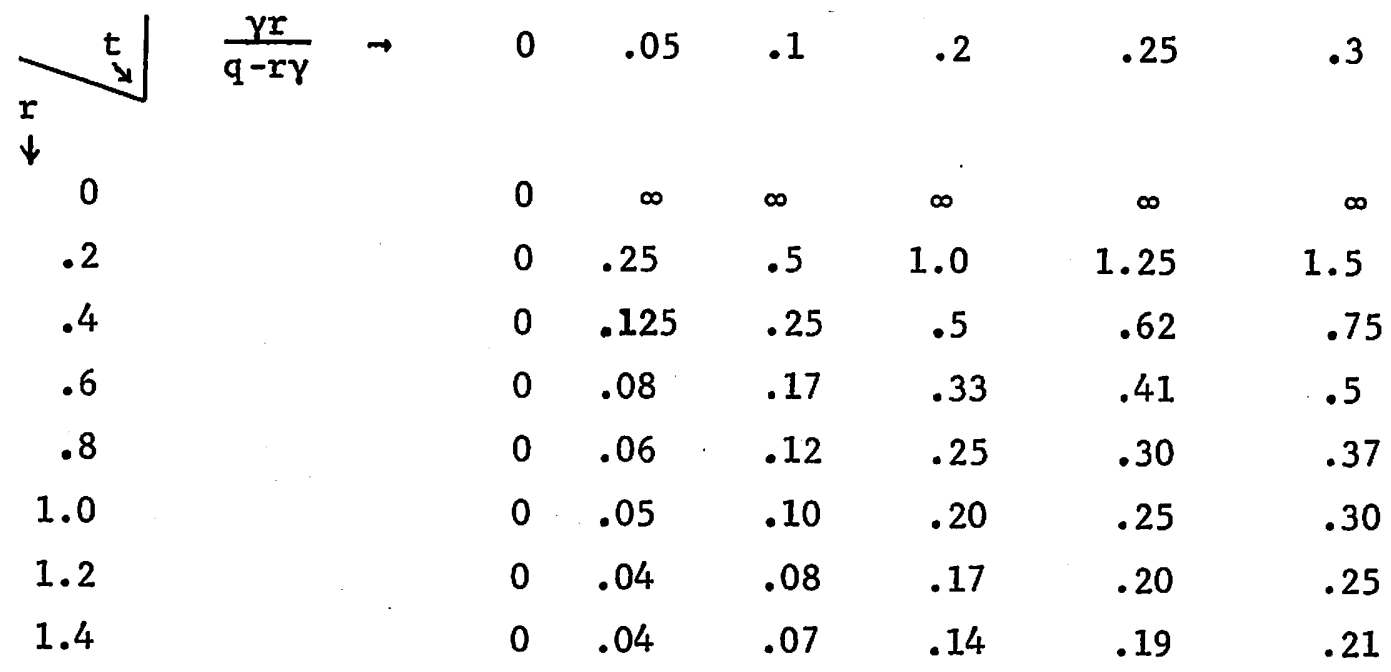


Even if inequality (24) holds, an increase in public output in the high-service jurisdiction may not cause immigration to that jurisdiction. That is because the increase in public output $z_{2}$ now has a direct effect on housing prices. Applying Cramer's Rule to equations (6) and (7), holding $y_{1}$ constant (henceforth $\frac{\partial Q_{i}}{\partial z_{i}}$ will refer to the direct effect, holding $y_{1}$ constant),

$$
\frac{\partial Q_{2}}{\partial z_{2}}=\frac{1}{\Delta_{2}} \frac{\overline{\mathrm{L}}_{2}}{\gamma\left(\mathrm{r}_{2}\right)} \quad \gamma^{\prime}\left(\mathrm{r}_{2}\right) \mathrm{P}_{2} \geq 0
$$

where $\Delta_{2}$ is the determinant defined as in equation (20) for the high service jurisdiction.

Thus the direct effect of an increase in $z_{2}$ may be to lower the utility of the marginal resident living in the high service jurisdiction, if the disutility of increased rents exceeds the utility gain from more public output. In that case, marginal residents would be induced to move to the low service jurisdiction, raising housing prices there (if $\frac{\partial Q_{1}}{\partial y_{1}}>0$ ). Thus whether the direction of immigration is the same as in the fixed-coefficients case depends on (i) inequality (24) and (ii) the direct effect on the utility of the marginal resident. This latter effect can be written

$$
\Delta V\left(y_{1}, Q_{2}, z_{2}\right)=\left[\phi\left(y, Q_{2}, z_{2}\right)-\frac{\partial Q_{2}}{\partial z_{2}} h\left(y, Q_{2}\right)\right] \lambda\left(y, Q_{2}, z_{2}\right)
$$

where $\lambda$ is the marginal utility of income, $\varnothing$ is the marginal rate of substitution of the public good for the private, and Roy's identity has be used. If inequality (24) holds, then $\gamma^{2} h>-\gamma^{\prime}$ tqh. ${ }^{12}$ This implies $\gamma^{2} h \frac{\eta}{Q}+\gamma^{\prime}\left(r_{2}\right) h \underset{Q}{\stackrel{q t \eta}{Q}} 0$. Using the fact that $\frac{q t}{Q}=\frac{t}{1+t}$, and the definition of $\Delta_{2}$, this then implies 
(27)

$$
\Delta_{2}<-\frac{\gamma^{\prime}\left(r_{2}\right)}{\gamma\left(r_{2}\right)} \quad q_{2} \bar{L}_{2}\left(\int_{y_{1}}^{y} h\left(y, Q_{2}\right) f(y) d y\right)
$$

If $\bar{h}_{2}$ is the average housing consumption in the high-service jurisdiction, (27) and the definition (25) then imply

(28) $\quad \overline{\mathrm{h}}_{2} \frac{\partial \mathrm{Q}_{2}}{\partial \mathrm{z}_{2}}<1$

The expression in (26) will then have a positive sign if the ratio of the marginal resident's housing consumption to the average in the high-service jurisdiction $h\left(y_{2}, Q_{2}\right) / \bar{h}_{2}$ is less than his/her marginal rate of substitution $\phi$. This expression being positive would mean that immigration to the high-service jurisdiction would result from the public output increase. By the same reasoning used in the fixed-coefficient case, every renter's utility would be increased by the public output increase.

Theorem 5: If $t_{i} \sigma \leq \alpha_{i}(i=1,2)$ where $t_{i}$ is the property tax rate, $\sigma$ the elasticity of substitution in housing production, and $\alpha_{i}$ land's share in housing costs, and $h\left(y_{1}, Q_{2}\right) \leq \phi\left(y_{1}, Q_{2}, z_{2}\right) \bar{h}_{2}$ where $\phi$ is the marginal rate of substitution of public output for the numéraire then an increase in per capita public output in the high-service jurisdiction will increase all renters' utility.

The conditions of the theorem are not necessary for the result. But the second condition is quite strong. The slope of the indifference curves in Figure 1 is $\phi(y, Q, z) / h(y, Q)$. Normal stratification thus implies $\phi / h$ increases with income. Thus if the condition of the theorem, $\phi\left(y_{1}, Q_{2}, h_{2}\right) / h\left(y_{1}, Q_{2}\right)$ $\geq 1 / \overline{\mathrm{h}}_{2}$ holds, then $\phi / \mathrm{h}>1 / \overline{\mathrm{h}}_{2}$ for every resident in the high-service jurisdiction. It thus must be true then $\int_{y_{1}}^{y} \phi\left(y, Q_{2}, z_{2}\right) f(y) d y>\left(\int_{y}^{y}{ }_{1} h\left(y, Q_{2}, z_{2}\right) f(y) d y\right) / \bar{h}_{2}$. 
But this is precisely $\sum \mathrm{MRS}_{2}>\mathrm{MRT}_{2}$. Therefore if there is:an oversupply of the public output ( MMRS < MRT) in the high-service jurisdiction, the conditions of the theorem do not apply. Since these conditions are not necessary, no insight is gained as to whether renters' common interest dictates an oversupply (using the conventional $\Sigma$ MRS $=$ MRT rule) of the public output in the high-service jurisdictions. Alternatively, there are situations where it is in all renters' interest to upgrade the high-service jurisdiction's public output, but these are situations when simple costbenefit calculations would also justify the increase.

The above results suggest the effects of public output increases in renters' welfare are as follows. Fix $z_{1}$, and let $z_{2}$ increase. As long as the conditions of the theorem hold, all renters' utility increases as $z_{2}$ increases. So does the population of the high-service jurisdiction. But eventually there is some $\hat{z}_{2}\left(z_{1}\right)$ where $\phi\left(y_{1}, Q_{2}, \hat{z}_{2}\right)-\frac{\partial Q_{2}}{\partial z_{2}} h\left(y_{1}, Q_{2}\right)=0$, where $y_{1}$ and $Q_{2}$ are the cut-off income level and housing price associated with $\left(z_{1}, \hat{z}_{2},\left(z_{1}\right)\right)$. Here an increase, in public output has no direct effect on the marginal resident's utility, so that $\partial y_{1} / \partial z_{2}=0$. It is plausible that for higher values of $z_{2}$ the expression $\phi-\frac{\partial Q_{2}}{\partial z_{2}} h$ becomes negative for the marginal resident. Then $\hat{z}_{2}$ maximizes both the population of the high-service jurisdiction, and the utility of all renters who choose the low-service jurisdiction (at $\left(z_{1}, \hat{z}_{2}\left(z_{1}\right)\right.$ ). As $z_{2}$ rise above $\hat{z}_{2}$, immigration to the low-service jurisdiction raises rents there--if inequality (24) holds-making all residents there worse off. However, high-income residents of jurisdiction 2, who value the service increases more heavily (relative to the rent increases) will still be better off. Figure 3 shows the level of public output $z_{2}^{*}\left(y, z_{1}\right)$ which maximizes the utility of person $y$. It is equal to $\hat{z}_{2}\left(z_{1}\right)$ for $y \leq y_{1}\left(z_{1}, z_{2}\right)$ and rises with $y$ above that. 
27

Figure 3

level of $z_{2}$ which maximizes $u$ (for given $z_{1}$ )

-

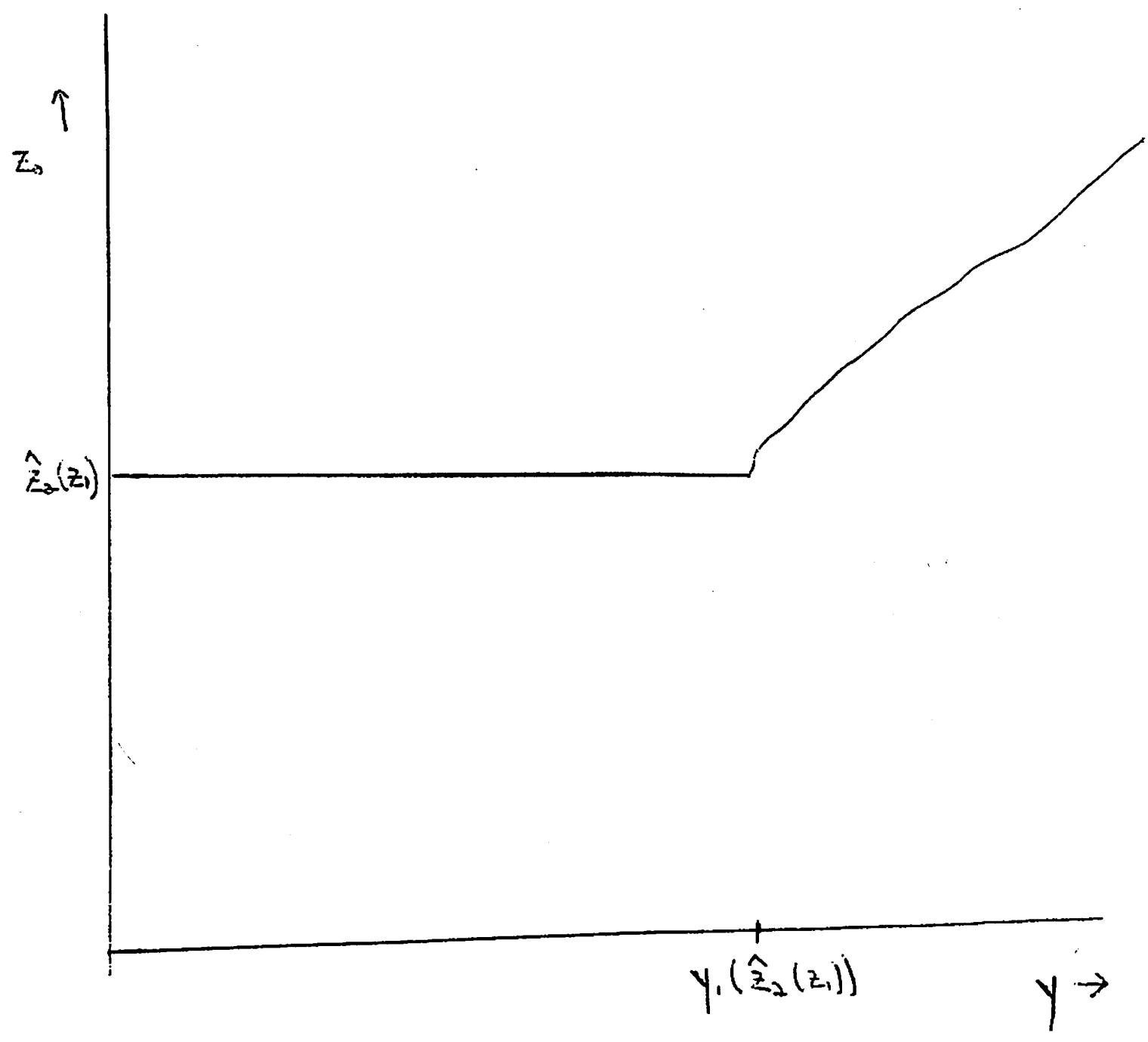


Above, it was implicitly assumed that $\hat{z}_{2}\left(z_{1}\right)>z_{1}$. In general, this is not the case. But it will now be shown that under certain conditions it will always be optimal for all renters to have $z_{2}>z_{1}$. That is, if $\hat{z}_{2} \leq z_{1}$, then $z_{1}$ can be lowered to increase all renters' utility. Since this requires some additional assumptions, and refers only to renters' utility, it is a much weaker result than those obtained for the fixed-coefficient case. The conditions required are

(i) inequality (24) holds

(ii) the price elasticity $\eta$ of housing demand does not vary with income

(iii) the elasticity of substitution $\sigma$ in housing production is constant, and less than or equal to 1

(iv) federal subsidies are zero.

These conditions are by no means necessary for the result.

The result follows from the fact that $\frac{\partial Q_{i}}{\partial z_{i}}$ will be lower in jurisdiction 2 than in jurisdiction 1 , if $Q_{1}=Q_{2}, z_{1}=z_{2}$ and conditions (i) -(iv) hold. From this it will follow that either an increase in $z_{2}$ or a decrease in $z_{1}$ will increase every renter's utility. The definition (20) of the determinant $\Delta_{i}$, the definition (25) of $\frac{\partial Q_{i}}{\partial z_{i}}$, and some manipulation yield

$$
-\left(\frac{\partial Q_{i}}{\partial z_{i}}\right)^{-1}=\bar{h}_{i}\left\{\left(\frac{\gamma^{2}}{\gamma Q_{i}}+\frac{t_{i}}{1+t_{i}}\right) \eta-1\right\}
$$

This holds in each jurisdiction. If $z_{1}=z_{2}$, equilibrium requires $Q_{1}=Q_{2}$. From normality of housing demand $\bar{h}_{1}<\bar{h}_{2}$. With no federal subsidies, $z_{i}=t_{i} q_{i} \bar{h}_{i}$, so that $t_{1} q_{1}>t_{2} q_{2}$. Therefore $q_{2}>q_{1}$ (since $\left.Q=q+t q\right)$, so that $r_{2}>r_{1}$. What must be shown is that $\frac{\gamma^{2}}{\gamma^{\prime} Q}+\frac{t}{1+t}$ is smaller in absolute value in the low-service jurisdiction. From inequality (24), this term must be negative. ${ }^{13}$ since 
$r_{2}>r_{1}$ and $t_{1} q_{1}>t_{2} q_{2}$, then $\frac{t_{1}}{1+t_{1}}>\frac{t_{2}}{1+t_{2}}$. Therefore $\left|\frac{\gamma^{2}}{\gamma^{2} Q}\right|_{2}>\left|\frac{\gamma^{2}}{\gamma^{\prime} Q}\right|_{1}$ is sufficient for my result. From the definition of $\sigma$ (equation (23)), $\frac{\gamma^{2}}{\gamma^{\prime} Q}=-\frac{1}{\sigma} \frac{1}{1+t} \frac{\alpha}{1-\alpha}$ where $\alpha$ is land's share in housing costs. Since $\sigma<1$, the factor share ratio $\frac{\alpha}{1-\alpha}$ rises with $r$. Therefore it is higher in jurisdiction 2 , as is $\frac{1}{1+t}$. If $\sigma$ is constant, this then implies, using the definition (29) that $\frac{\partial Q_{1}}{\partial z_{1}}>\frac{\partial Q_{2}}{\partial z}$.

If $\phi\left(y_{1}, Q_{2}, z_{2}\right)>h\left(y_{1}, Q_{2}\right) \frac{\partial Q_{2}}{\partial z_{2}}$, then an increase in $z_{2}$ has been shown to increase everyone's welfare. On the other hand if $\phi\left(y_{1}, Q_{2}, z_{2}\right) \leq h\left(y_{1}, Q_{2}\right) \frac{\partial Q_{2}}{\partial z_{2}}$, then (since $\left.z_{1}=z_{2}, Q_{1}=Q_{2}\right)$, from the above result $\phi\left(y, Q_{1}, z_{1}\right)<h\left(y_{1}, Q_{1}\right) \frac{\partial Q_{1}}{\partial z_{1}}$. This implies any decrease in public output in jurisdiction 1 will raise everyone's welfare. It will be preferred by all residents of the low-service jurisdiction, and the immigration it induces from the high-service jurisdiction will lower rents there. This establishes the theorem. However, a weakness should be noted. No attention has been paid, as was earlier, to the possible equilibria not involving income segregation when $z_{1}=z_{2}$. The above result only applied to cases where $\overline{\mathrm{h}}_{1} \neq \overline{\mathrm{h}}_{2}$. It can be stated as Theorem 6: Under conditions (i)-(iv) above, there is some equilibrium involving differential public output provision $\left(z_{2} \neq z_{1}\right)$ which is preferred by all renters to any equilibrium with $z_{2}=z_{1}$ and some income segregation.

VI. A Digression on Tax Base Equalization

This theorem depended on the absence of central government funding. By contrast, consider what occurs when full tax base equalization occurs. That is, instead of giving out fixed per capita subsidies $s_{i}$, suppose the subsidies $s_{i}$ are so designed as to make the required tax rate for a given 
public output level independent of the jurisdiction. If $\bar{b}$ is some "guaranteed" per capita tax base, then a jurisdiction's subsidy per capita is $t_{i}\left(\bar{b}-q_{i} \bar{h}_{i}\right)$ which is endogenous. This policy has been widely propounded as one to redress inequalities in the local public sector. Here I will deal only with the effects of such a policy on local public output provision. I will show that in general it will not be in renters' interest, under such a policy, to equalize these outputs .

If tax base equalization is in force, the local public sector's budget constraint becomes

$$
z_{j}=t_{j} \bar{b}
$$

assuming local residents ignore the effects on their own income of increased federal equalization payments. This constraint replaces the original equation (7). It then follows that ${ }^{14}$

$$
\left.-\left(\frac{\partial Q_{i}}{\partial z_{i}}\right)^{-1}=\frac{\bar{b}}{q\left(r_{i}\right)}\left\{\eta \frac{\gamma^{2}}{\gamma^{\prime} Q_{i}}+\frac{t \gamma^{2}}{\gamma^{\prime} Q_{i}}\right)-1\right\}
$$

Suppose the two jurisdictions had identical public output levels $z$. Then equilibrium requires $Q_{1}=Q_{2}$. From (30), $t_{1}=t_{2}$, so that $r$ and $\gamma$ must be the same in each jurisdiction. If the price elasticity $\eta$ of housing demand is the same in both jurisdictions, then from (31), so will be $\frac{\partial Q_{i}}{\partial z_{i}}$. If $\phi\left(y_{1}, Q_{i}, z_{i}\right)>h\left(y_{1}, Q_{i}\right) \frac{\partial Q_{i}}{\partial z_{i}}$ in both jurisdictions, then an increase in $z_{2}$ would make everyone better off. If $\phi<h \frac{\partial Q}{\partial z}$ then a decrease in $z_{1}$ would make everyone better off. Only, in general, for one value of $z_{1}$ will $\hat{z}_{2}\left(z_{1}\right)=z_{1}$. Only one point on the whole Pareto-optimal (for renters) frontier will involve equality of expenditure. And even here the very poor would prefer more inequality (lower $z_{1}$ ) as would the rich (higher $z_{2}$ ). 
Only residents marginal between jurisdictions would prefer equality of public output under tax base equalization, and then, as mentioned, only at the fortuitous level of $z_{1}$ where $\phi=h \frac{\partial Q}{\partial z}$. The only assumption required for this was that $\eta$ be the same in both jurisdictions.

VII. Adding Up Benefits With Variable-Coefficient Housing Production

Returning to the situation where subsidies are constant, something should be said about the effects on land owners. Unfortunately nothing unambiguous will be said. An expression can be derived for the change in the "benefit-cost" measure of social welfare used before due to public output level changes in one jurisdiction or other. This expression will have more terms than the one derived in the fixed-coefficient case, with the additional terms representing changes induced in the welfare loss due to the property tax.

As before the effect on everyone's (renters, land owners and taxpayers) welfare due to changes in population in the low service jurisdiction caused by a public output increase in the high-service jurisdiction can be written

$$
\frac{\partial W_{1}}{\partial z_{2}}=\frac{\partial y_{1}}{\partial z_{2}}\left[-\frac{\partial Q_{1}}{\partial y_{1}} \frac{\bar{L}_{1}}{\gamma_{1}}+\bar{L}_{1} \frac{\partial r_{1}}{\partial y_{1}}-s_{1} f\left(y_{1}\right)\right]
$$

From the definition of $Q(=q(x)+t q(r))$, the local budget constraint (7) and the definition of $\sigma$ (23), this can be written

$$
\frac{\partial w_{1}}{\partial z_{2}}=\frac{\partial y_{1}}{\partial z_{2}}\left[-z_{1} f\left(y_{1}\right)+\left(\frac{t_{1} \bar{L}_{1}}{\alpha_{1}}\right) \sigma_{1} \frac{\partial r_{1}}{\partial y_{1}}\right]
$$

where $\alpha$ is land's share in housing costs. Including both the indirect effect (through $y_{1}$ ) and the direct effect, the effect of the change in $z_{2}$ on welfare in jurisdiction 2 can be shown--by a similar series of steps--to equal 
(34)

$$
\begin{aligned}
\frac{\partial \mathrm{W}_{2}}{\partial \mathrm{z}_{2}} & =\Sigma \mathrm{MRS}_{2}-\mathrm{MRT}_{2}+\frac{\partial \mathrm{r}_{2}}{\partial \mathrm{z}_{2}}\left(\frac{\mathrm{t}_{2} \overline{\mathrm{L}}_{2}}{\alpha_{2}}\right) \sigma_{2} \\
& +\frac{\partial \mathrm{y}_{1}}{\partial \mathrm{z}_{2}}\left[\mathrm{z}_{2} \mathrm{f}\left(\mathrm{y}_{1}\right)-\left(\frac{\mathrm{t}_{2} \overline{\mathrm{L}}_{2}}{\alpha_{2}}\right) \sigma_{2} \frac{\partial \mathrm{r}_{2}}{\partial \mathrm{y}_{1}}\right]
\end{aligned}
$$

Combining (33) and (34), the overall effect on welfare of the public output increase is

$$
\begin{aligned}
\frac{\partial W}{\partial z_{2}} & =f\left(y_{1}\right)\left(z_{2}-z_{1}\right) \frac{\partial y_{1}}{\partial z_{2}}+\left(\Sigma M_{2}-M_{R} T_{2}\right)+\sigma_{1} \frac{t_{1} \bar{L}_{1}}{\alpha_{1}} \frac{\partial r_{1}}{\partial y_{1}} \\
& +\left(\frac{t_{2} \bar{L}_{2}}{\alpha_{2}} \sigma_{2}\right)\left(\frac{\partial r_{2}}{\partial z_{2}}-\frac{\partial y_{1}}{\partial z_{2}} \frac{\partial r_{2}}{\partial y_{1}}\right)
\end{aligned}
$$

The last terms represent the changes in the welfare loss due to the property tax. To see this, compare the welfare from raising tax revenue for a given public output level $z$ by a head tax and a property tax. Let the superscripts " $h$ " and "p" refer to these cases. The utility loss to a person of income $y$ residing in the town is

$$
\Delta V=V\left(y-z, Q^{h}, z\right)-V\left(y, Q^{p}, z\right)
$$

whereas the difference in income of landlords is

$$
\Delta I=\frac{\bar{L}}{\gamma}\left(r^{h}-r^{p}\right)
$$

If the population parameter $y_{1}$ changes, leaving $z$ unchanged, the total change in the welfare loss is

$$
\frac{\partial(W L)}{\partial y_{1}}=\int \frac{\partial(\Delta V)}{\partial z} \frac{1}{\lambda} d y+\frac{\partial(\Delta I)}{\partial z}
$$

where the integration is over the jurisdiction's population, and $\lambda$ is the marginal utility of income. 15 From Roy's identity and (36), 


$$
\frac{\partial(\Delta V)}{\partial y_{1}} \frac{1}{\lambda}=-h\left(y, Q^{h}\right) \frac{\partial Q^{h}}{\partial y_{1}}+h\left(y, Q^{p}\right) \frac{\partial Q^{p}}{\partial y_{1}}
$$

Since $\int h=\bar{L} / Y$, and $\frac{\partial r^{h}}{\partial y_{1}}=\frac{\partial Q^{h}}{\partial y_{1}}$ (since $t^{h}=0$ here), the effects involving the head $\operatorname{tax}$ In (38) cancel. This leaves

(40) $\frac{\partial(W L)}{\partial y_{1}}=\left(t^{p_{q}}{ }^{p}\right)\left(\frac{x^{\prime}}{\gamma^{2}}\right) \bar{L} \frac{\partial r^{p}}{\partial y_{1}}$

(using equations (6), (7) and the definition of Q). Fron the definition of $\sigma$ this equals $-\left(\frac{t \overline{\mathrm{I}}}{\alpha}\right) \sigma \frac{\partial \mathrm{r}}{\partial \mathrm{y}_{1}}$ as in equation (35). Thus the additional terms in (35) measure changes induced in property tax distortions.

\section{Conclusions}

It has long been accepted that some varlety in public goods provision across jurlsdictions is efficient when there are no economies of scale in public good supply. This view can be attribited to Tiebout. What this paper has done is extend (qualified) support for this view In several directions. Most important, it has emphasized that equity considerations need not act In the opposite direction. Given nobility, and normal stratification, the interests of low-income renters are best served by considerable disparity in local public good provision. This result does not depend on the assumption, in the first part of the paper, that the property tax can be passed on to land owners. It holds under fairly general conditions when that assumption is relaxed. A1so, the fact that low Incone people might prefer a lowering of their jurisdiction's per capita public outp:1t--quite plausible in this nolel--certainly does not seem an obvious result of belng able to pass on the property tax burden. 
It also is not true in this model that the jurisdictions are the endogenous, optimal partitions of the population envisioned by Tiebout. Instead the more realistic assumption of exogenously given jurisdictions allows for the fact that forming new comunuitles (or altering old ones) may be very difficult. Also, taxes here are not ldeal head taxes, but property taxes, again corresponding to reality. These property taxes cause distortions which conplicate the results, but these are clearly conplications which must be faced, if the current local dependence on the real property tax is regarded as immutable.

What should be emphasized is that, to a prospective imnigrant, the property tax bill is not the price of the local public goods consumed. The price of the local public sector is the hoising price. This fact holds even when there are variable proportions in housing, and when the Iminigrant intends to buy the house. And this 18 why the poor may suffer from improvements In the local public sector (or any other local amenlties). Now Immigrants with a strong taste for local public goods will bid up the price of their housing. The very fact that the low-incone people chose to IIve in a low-service jurisdiction reflects (in this nodel) their unwillingness to pay high housing prices for an attractive local public sector.

The previous paragraph highlights the crucial role of mobility in this paper. Its conclusions are vitiated if the inhabitants of low-service jurisdictions do not have the choices assumed here. Restrictive zoning, slowness of the housing stock to adjust and other housing market imperfections may determine location. Nonetheless, to the extent that there is some nobility (not necessarily for everyone), improving the amenities in "property poor" jurisdictions may be "gentrification" which benefits the upper and middle classes at the expense of the previous low-incone inhabitants. 


\section{Appendix}

Suppose there are $\mathrm{J}$ jurisdictions, and jurisdiction $\mathrm{j}(\mathrm{j}<\mathrm{J}$ ) ralses per capita public output.

$Q_{\mathrm{J}}$ cannot rise.

If $Q_{J}$ rose, then people must have immigrated there, so that $y_{J-1}$ has fallen. It must therefore be that $Q_{J-1}$ rose (to explain the immigration). Since $Q_{J-1}$ rose, population must have risen, implying $y_{J-2}$ fell. (Since $P_{j}=\int_{y_{j-1}}^{y_{j}} f(y) d y$, and $\left.y_{J-1} f e l 1\right)$.

Therefore if $Q_{J}$ rose, so did $Q_{J-1}, \ldots, Q_{j+1}$. And $y_{J-1}, \ldots, y_{j}$ must

all have fallen.

Since people are leaving jurisdiction $j$ to go to jurisdiction $j+1$, even though $Q_{j+1}$ rose and $z_{j}$ rose, it must be that $Q_{j}$ rose. So $y_{j-1}$ must have fallen to cause this.

The person in jurisdiction $j$ with the steepest indifference curve (in $z-Q$ ) space) has characteristic $y_{j}$, and he/she emigrated to a jurisdiction whose rent rose. So $(\partial v / \partial z) \Delta z_{j}+(\partial V / \partial z) \Delta Q_{j}<0$ for $h 1 m / h e r$. This also must be true (since $\Delta z_{j}>0, \Delta Q_{j}<0$ ) for the person with shallower indifference curves, $y_{j-1}$, who chose to immigrate to jurisdiction $j-1$. Therefore his/her other cholce, jurisdiction $j-1$ must have jotten less attractive, so that $Q_{j-1}$ must have increased. As before, this must have been caused by a fall in $y_{j-2}$ and so on. Hence $Q_{j-1}, \ldots, Q_{1}$ must have increased. And $y_{j-2}, \ldots, y_{1}$ decreased.

But if $y_{1}$ fell, $Q_{1}$ must have decreased, since $P_{1}=\int_{0}^{y_{1}} f(y) d y$. Thus a contradiction has been established. Note this holds even if $j=1$, since then, above, $Q_{j}$ was shown to have increased and $\dot{y}_{j}$ decreased. So $Q_{J}$ must have decreased, and $y_{J-1}$ increased. 
(2) $Q_{j+1}, \ldots, Q_{J}$ all have decreased. $y_{j}, \ldots, y_{J-1}$ have all Increased.

If $Q_{k+1}, \ldots Q_{J}$ have all decreased $(k>j)$ and $Q_{k}$ increased, it must be that $\mathrm{y}_{\mathrm{k}-1}$ decreased, to increase $\mathrm{P}_{\mathrm{k}}$.

Then the proof of (1) can be applied, with $k$ replacing $J$.

(3) If $y_{j-1}$ has increased then $Q_{1}, \ldots, Q_{j-1}$ have all increased.

An Increase in $y_{j-1}$ and a decrease in $Q_{j-1}$ would mean $y_{j-2}$ Increased, and $Q_{j-2}$ decreased (since people emigrated from j-1 to $j-2$ ). This would mean $Q_{j-3}, \ldots, Q_{1}$ decreased and $y_{j-2}, \ldots, y_{1}$ increased. But again this is inconsistent with jurisdiction 1.

So $Q_{j-1}$ must have decreased and $y_{j-2}$ increased.

Repetition of the above argument establishes $Q_{1}, \ldots, Q_{j-1}$ must all increase, and $y_{1}, \ldots, y_{j-2}$ all increase.

(4) If $y_{j-1}$ has decreased, then $Q_{1}, \ldots, Q_{j-1}$ have all increased.

If $Q_{j-1}$ increased, then $y_{j-2}$ would have had to decrease, and the same contradiction of sections (1) $-(3)$ can be established.

(5) If $y_{j-1}$ has decreased, all renters' utility has increased.

This clearly is true for residents of all jurisdictions other than $j$. The resident of characteristic $y_{j-1}$ 's utility has increased (since there has been migration from jurisdiction $j-1$, where rents fell). Sor for him/her the $108 s$ of utility due to the rent increase is overcome by the effects of the public output increase. Since Indifference curves get steeper as y increases, this must be true for all residents of furisdiction $j$.

(6) If $y_{j-1}$ has increased, utility has fallen for all renters of characteristic below $\hat{y}$ with $y_{j-1}<\hat{y}<y_{j}$ (and risen for all others). Sections (2) and (4) establish the result for residents not in jurisdiction $j$. There the immigration 
at the high-service end, the emigration at the low-service end, and the familiar "steeper indifference curve" argument prove the result.

(7) If $j=J$, all rents in jurisidictions $1, \ldots, J-1$ must fall after an increase in $z_{\mathrm{J}}$.

If $y_{\mathrm{J}-1}$ decreases, the result follows (as in section (4)). If it has Increased, $Q_{J}$ must have fallen. Since $Q_{J}$ has fallen, and $z_{J}$ risen, and there has been emigration from jurisdiction $J, Q_{J-I}$ must have fallen. This (and the assumption $\mathrm{y}_{\mathrm{J}-1}$ has increased) establish the contradictory results that $Q_{1}$ has fallen and $y_{1}$ increased.

(8) All renters' utility rises after an increase in $z_{\mathrm{J}}$.

This is an immediate corollary of section (7), using the "steeper indifference curve" argument. 


\section{Fontnotes}

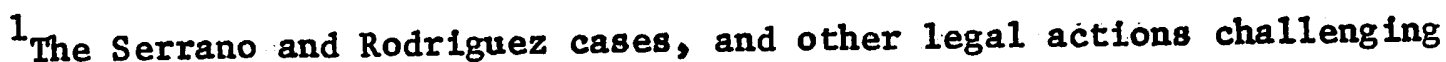
the local property tax are the best evidence of this. The increasing role played by stateiand provincial governments in financing the local public sector, whether or not under judicial order, also can be attributed to an intent to reduce disparities in local government spending per capita.

2 The influential book by Clune, Coons and Sugarman (1970) is a good example. The studies in Lindholm (1974) also assume this view. Feldstein (1975) justifles this sort of view in terms of "categorical equity".

$3_{\text {The effects of increased central government expenditure on local }}$ residents will be ignored. Either they don't bear the burden of taxes used to ralse this revenue, or (more plausibly) the metropolitan area is small relative to the central government.

${ }^{4}$ It is assumed housing is a homogeneous commodity.

$5_{\text {From section IV onward. }}$

${ }^{6}$ In Chapter 2 of my dissertation, pp. 40-46.

${ }^{7}$ Cost minimization means the Langranglan

$$
r \gamma+\mu+\lambda(g(\gamma, \mu)-1)
$$

is minimized. Therefore

$$
\begin{aligned}
& \mathbf{x}+\lambda \frac{\partial g}{\partial \boldsymbol{\gamma}}=0 \\
& 1+\lambda \frac{\partial g}{\partial \mu}=0
\end{aligned}
$$

So that $\frac{\partial g}{\partial \gamma}=r \frac{\partial g}{\partial \mu}$. Since $g(\gamma(r), \mu(r)) \equiv I, \frac{\partial g}{\partial \gamma} \gamma^{\prime}(r)+\frac{\partial g}{\partial \mu} \mu^{\prime}(r)=0$. Since $q(r)=r \gamma+\mu(r), q^{\prime}(r)=r \gamma^{\prime}(r)+\mu^{\prime}(r)+\gamma(r)$ And $\left(r \gamma^{\prime}(r)+\mu^{\prime}(r)\right)=\frac{\partial g}{\partial \mu} \gamma^{\prime}(r)+\frac{\partial g}{\partial \mu} \mu^{\prime}(r)=0$. 
${ }^{8}$ See Hirsch (1968) for a summary of this.

9 Even though the public good here has a pure private good technology, all residents of a jurisdiction must consume it at the same level. Thus for a single jurisdiction financing $z$ by a non-distortionary, non-exportable tax, the condition for Pareto optimality is $\Sigma M R S=M R T$, if MRT is the aggregate cost of additional public good units to all the population.

${ }^{10}$ Let $D(y, Q, \phi)$ be the "demand" for the public good at "price" $\phi$. By definftion

$$
D(y, Q, \phi(y, Q, z)) \equiv z
$$

Varying $y$,

$$
\frac{\partial D}{\partial y}+\frac{\partial D}{\partial \phi} \frac{\partial \phi}{\partial y}=0
$$

Thus if the public good is normal, $\frac{\partial \phi}{\partial y}>0$.

${ }^{11}$ If $\xi$ is the tax rate as a fraction of value, $V$ is value and $\rho$ the interest rate, then

$$
\begin{aligned}
q & =\rho V \text { and } t q=\xi V \\
\text { So } t & =\frac{\xi V}{q}=\frac{\xi}{\rho}
\end{aligned}
$$

Thus a $2 \%$ property tax rate (as fraction of value), and $5 \%$ interest rate Imply $t=.4$.

$$
\begin{aligned}
& { }^{12} \text { Since } t \sigma<\frac{r \gamma}{q-r \gamma^{\prime}} \text {, then from (23) } \\
& -\frac{t \gamma^{\prime}}{\gamma}=\frac{t \sigma}{r}\left(\frac{q-r \gamma}{q}\right)<\frac{\gamma}{q} \\
& 80-\gamma^{\prime} t q<\gamma^{2} \\
& 13 \text { Footnote (12) shows inequality (24) implies }-\gamma^{\prime} \text { tq }<\gamma^{2} \\
& \text { therefore }-t q<\frac{\gamma^{2}}{\gamma^{\prime}} \\
& \text { divide by } Q \quad-\frac{t q}{Q}=-\frac{t}{1+t}<\frac{\gamma^{2}}{\gamma^{\prime} Q}
\end{aligned}
$$


${ }^{14}$ F rom $(30), \frac{\partial t}{\partial z}=\frac{1}{b}$

Since $L=\gamma \int h(y, Q) f(y) d y$

then

$$
\gamma^{\prime} \int h \frac{\partial r}{\partial z}+\left(\gamma \int \frac{\partial h}{\partial Q} f(y) d y\right) \frac{\partial Q}{\partial z}=0
$$

since

$$
\begin{aligned}
& \frac{\partial h}{\partial Q}=-\frac{h}{Q} \eta \text { and } \int h=\frac{L}{\gamma} \\
& \frac{\gamma^{\prime}}{\gamma} \frac{\partial r}{\partial z}-\frac{\partial Q}{\partial z} \frac{\eta}{Q}=0
\end{aligned}
$$

and

$$
\frac{\partial Q}{\partial z}=\gamma \frac{\partial r}{\partial z}(1+t)+q \frac{\partial t}{\partial z}=\gamma(1+t) \frac{\partial r}{\partial z}+\frac{q}{b}
$$

So

$$
\frac{\partial r}{\partial z}=\frac{1}{\gamma(1+t)}\left(\frac{\partial Q}{\partial z}-\frac{q}{b}\right)
$$

And $\quad \frac{\partial Q}{\partial z}\left(\frac{\gamma^{\prime}}{\gamma^{2}} \frac{1}{1+t}-\frac{\eta}{Q}\right)-\frac{\gamma^{\prime}}{\gamma^{2}(1+t)} \frac{q}{b}=0$

So $\quad \frac{\gamma^{\prime}}{\gamma^{2}} \frac{1}{1+t}-\frac{\eta}{Q}=\left(\frac{q}{b}\right)\left(\frac{\gamma^{\prime}}{\gamma^{2}(1+t)}\right)\left(\frac{\partial Q}{\partial z}\right)^{-1}$

And $\left(\frac{\partial Q}{\partial z}\right)^{-1}=\frac{b}{q}-\frac{\eta}{Q} \frac{1+t}{\gamma^{\prime}} \gamma^{2}$

${ }^{15}$ As befits a "consumers' surplus" result, it is required that $\lambda$ be the same (for a person of given income) under both tax regimes. 


\section{References}

S. Bucovetsky (1979): "Optimal Jurisdiction, Housing and Mobility," processed. N. Burnstein (1978): "Voluntary Income Clustering and the Demand for Housing and Local Public Goods," processed.

J. Coons, W. Clune, and S. Sugarman (1970): Private Wealth and Public Education, (Cambridge, Massachusetts, 1970).

F. Edgeworth (1959): "The Pure Theory of Taxation," Chapter 17 in Muggrave and Shoup (eds): Readings in the Economics of Taxation, Irwin, 1959.

B. Ellickson (1971): "Jurisdictional Fragmentation and Residential Choice," American Economic Review, May 1971.

M. Feldstein (1975): "Wealth Neutrality and Local Cholce in Public Education" American Economic Review, 1975.

W. Hirsch (1968): "The Supply of Local Public Services," in H. Perloff and L. Wings (eds) Issues in Urban Economics (Baltimore, 1968).

R. Lindholm (ed) (1974): Property Taxation and the F1nance of Education

R. Richman (1967): "The Incidence of Urban Real Estate Taxes Under Conditions of Static and Dynamic Equilibrium," Land Economics, 1967. 


\section{Derivations of Results in Sections V-VII}

EQUATIONS 20,21

(i) Note $t q=Q-q(r)$

(1i) Then (6), (7) can be regarded as a system determining $Q, r$ as functions of $y_{1}, z$.

(ii1) (dropping subscripts)

$L-\gamma(r) \int h(y, Q) f(y) d y=0$

$\gamma(r)(z-8) \int f(y) d y-(Q-q(r)) L=0$

(iv) Differentiate

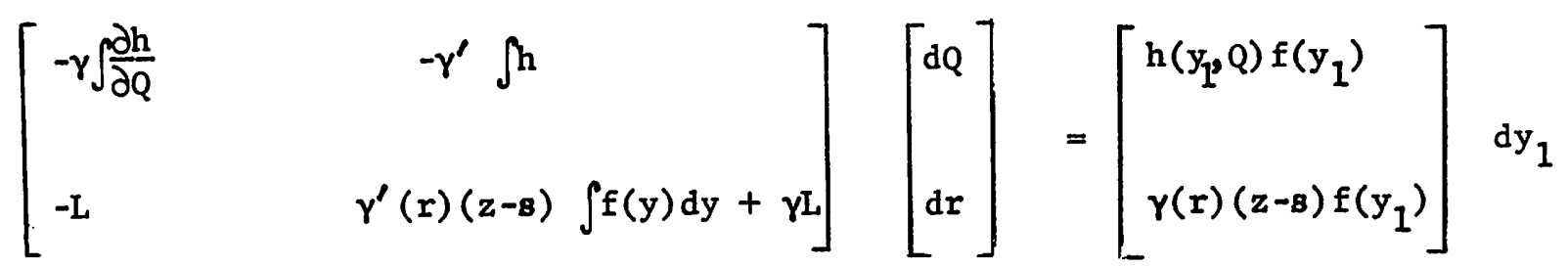

(v) Note

$$
(z-8) \int f(y) d y=\frac{t q L}{\gamma} \text { and }-\frac{\partial h}{\partial Q}=\eta \frac{h}{Q} \text { and } \int h=\frac{L}{\gamma}
$$

(vi) Substitute

$$
\left[\begin{array}{cc}
\frac{M L}{Q} & -\frac{\gamma_{-}^{\prime}}{\gamma} \\
-L & \frac{\gamma_{-}^{\prime} t q L+\gamma L}{\gamma}
\end{array}\right]\left[\begin{array}{l}
d Q \\
d r
\end{array}\right]=\left[\begin{array}{l}
\gamma h\left(y_{1}, Q\right) f\left(y_{1}\right) \\
-\gamma(r)(z-s) f\left(y_{1}\right)
\end{array}\right]
$$

(vii) From Cramer's Rule

$$
\begin{aligned}
& \frac{\partial Q}{\partial y}=\frac{A}{B} \text { with } \\
& B=\frac{L}{\gamma}\left(\frac{\Pi L}{Q} \quad \gamma^{\prime} \text { tq }+\frac{\pi L}{Q} \gamma^{2}-\gamma^{\prime} L\right)
\end{aligned}
$$

and $\quad A=f\left(y_{1}\right) L\left\{\gamma^{\prime} h\left(y_{1}, Q\right) t q+h\left(y_{1}, Q\right) \gamma^{2}-\gamma^{\prime}(r)(z-8)\right\}$

Since $L=\gamma \int h, B$ can be written 
43

$$
B=L \int\left[\gamma^{2} \frac{\eta}{Q}-\gamma^{\prime}+\eta \gamma^{\prime} \frac{t q}{Q}\right] h(y, Q) f(y) d y
$$

$$
\begin{aligned}
& \text { or } \left.\quad-\frac{\gamma}{q} \Delta_{1} \quad \text { (since } \frac{t q}{Q}=\frac{t}{1+t}\right) \\
& \text { But } \quad-\frac{q}{\gamma}(A)=f\left(y_{1}\right) q(r) L\left\{-h\left(y_{1}, Q_{1}\right) \gamma(r)+\frac{\gamma^{\prime}}{\gamma}(z-s)-\frac{\gamma^{\prime}}{\gamma} h\left(y_{1}, Q\right) t q\right\}
\end{aligned}
$$

So that

$$
\frac{-A /(q / \gamma)}{-B /(q / \gamma)} \text { is the expression in (21). }
$$

EQUATION 23

$$
\begin{aligned}
-\sigma & =\left(\frac{d(\gamma / \mu)}{d r}\right) \frac{r \mu}{\gamma} \\
& =\frac{\gamma^{\prime} \mu-\mu^{\prime} \gamma}{\mu^{2}} \frac{r_{\mu}}{\gamma}
\end{aligned}
$$

(where $\gamma, \mu$ are the factor proportions)

From footnote $7, r \gamma^{\prime}=-\mu^{\prime}$

So $\quad-\frac{\sigma}{r}=\frac{\gamma^{\prime} \mu+r \gamma^{\prime} \gamma}{\mu^{2}} \frac{\mu}{\gamma}$

$$
=\left(\frac{\gamma^{\prime}}{\gamma}\right)\left(\frac{\mu+r \gamma}{\mu}\right)
$$

But $\mu+r \gamma=q$ so $\mu=q-r \gamma$

So $\frac{\sigma}{r}=-\left(\frac{\gamma^{\prime}}{\gamma}\right)\left(\frac{q-}{q-r \gamma}\right)$

EQUATION 24

From (6), (7) (and the notes for equation $(20),(21)$ )

$$
\frac{\partial Q}{\partial z}=\frac{A}{B}
$$

$$
\begin{aligned}
& =\quad \text { where } B=-\frac{Y}{q} \Delta_{2} \\
& A=\operatorname{det}\left[\begin{array}{ll}
0 & -\frac{\gamma^{\prime}}{\gamma} \\
-\gamma P & \frac{\gamma^{\prime}}{\gamma} \operatorname{tqL}+\gamma L
\end{array}\right] \\
& =-\gamma^{l} \underline{\mathrm{PL}}
\end{aligned}
$$

so $\frac{\partial Q}{\partial z}=\frac{\gamma^{\prime} q}{\gamma} \frac{L}{\Delta} P$ 
EQUATION 28

From (25) and (27)

$$
\begin{aligned}
\frac{\partial Q_{2}}{\partial z_{2}}< & \frac{\gamma^{\prime} q P}{\gamma^{\prime} q(j h f(y) d y)} \\
& \int h f(y) d y=\bar{h}_{2} P \\
\text { so } \quad & \frac{\partial Q_{2}}{\partial z_{2}}<-\frac{1}{\bar{h}_{2}}
\end{aligned}
$$

EQUATION 29

$$
\begin{aligned}
\left(\frac{\partial Q}{\partial z}\right)^{-1} & =\frac{\gamma \Delta}{\gamma^{\prime} q L P} \\
\Delta & =-\frac{q L}{\gamma} \int\left(\gamma^{2} \frac{\eta}{Q}-\gamma^{\prime}+\gamma^{\prime} \eta \frac{t}{1+t}\right) h(y, Q) f(y) d y
\end{aligned}
$$

by definition $\int h(y, Q) f(y) d y=\vec{h} P$

$$
\text { So } \quad \begin{aligned}
-\left(\frac{\partial Q}{\partial z}\right)^{-1} & =\bar{h} \frac{q L\left(\gamma^{2} \frac{\eta}{Q}-\gamma^{\prime}+\gamma^{\prime} \eta \frac{t}{1+t}\right)}{\gamma^{\prime} q L} \\
& =\bar{h}\left\{\frac{\gamma^{2}}{\gamma^{\prime}} \frac{\eta}{Q}+\eta \frac{t}{1+t}-1\right\}
\end{aligned}
$$

EQUATION 33

$$
\frac{\partial Q}{\partial y}=\gamma \frac{\partial r}{\partial y}(1+t)+\frac{\partial t}{\partial y} q
$$

So $\quad-\frac{\partial Q}{\partial y} \frac{1}{\gamma}+\frac{\partial r}{\partial y}=-q \frac{\partial t}{\partial y} \frac{1}{\gamma}-t \frac{\partial r}{\partial y}$

Since tq $\frac{L}{\gamma}=(z-8) \int f(y) d y$

$$
\left(q \frac{\partial t}{\partial y}+t \frac{\partial q}{\partial y}\right) \frac{L}{\gamma}-\frac{\gamma^{\prime}}{\gamma^{2}} \mathrm{tqL} \frac{\partial \mathrm{r}}{\partial y}=(z-8)
$$

Then $-\frac{\partial Q}{\partial y} \frac{L}{\gamma}+\frac{\partial r}{\partial y} L=(z-s)-\frac{\gamma^{\prime}}{\gamma^{2}} \operatorname{tqL} \frac{\partial r}{\partial y}$ 
45

EQUATION 34

Since $\frac{\partial Q}{\partial z}=\gamma \frac{\partial r}{\partial z}(1+t)+\frac{\partial t}{\partial z} q$

Then (as above)

-

$$
-\frac{\partial Q}{\partial z} \frac{L}{\gamma}+\frac{\partial r}{\partial z}=-q \frac{\partial t}{\partial z} \frac{L}{\gamma}-t \frac{\partial q}{\partial z} \frac{L}{\gamma}
$$

And $\left(t \frac{\partial q}{\partial z}+q \frac{\partial t}{\partial z}\right) \frac{L}{\gamma}+\frac{\gamma^{\prime}}{\gamma^{2}} t q L \frac{\partial r}{\partial z}=\underline{P}$ (from budget balance)

So $\quad-\frac{\partial Q}{\partial z} \frac{L}{\gamma}+\frac{\partial r}{\partial z} L=-M R T+\left(\frac{t L}{\alpha}\right) \sigma \frac{\partial r}{\partial z}$ 
Notation: "Inequality in the Local Public Sector"

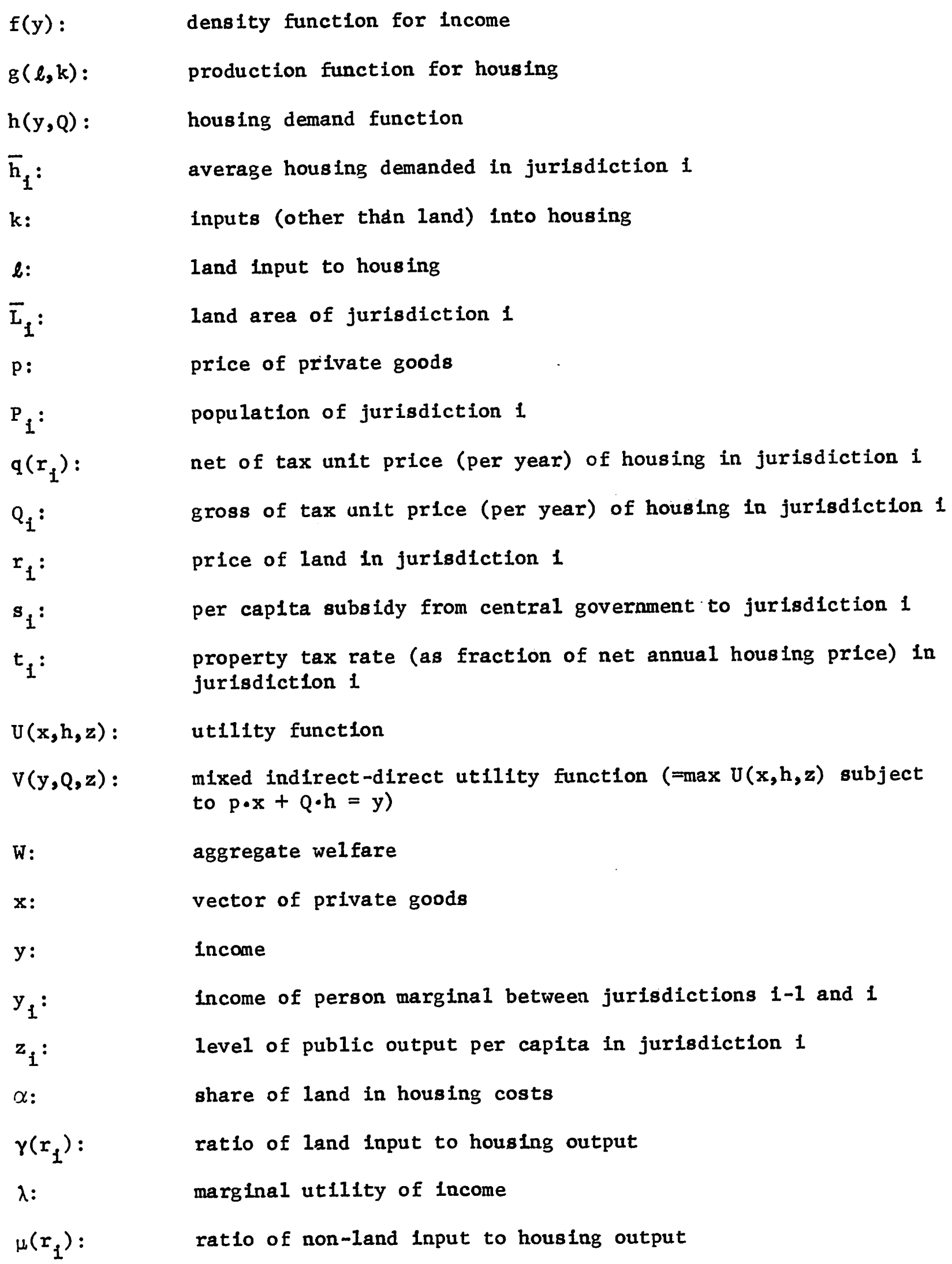


$\eta:$

$\sigma:$

$\varnothing$ :

absolute value of price elasticity of housing demand

absolute value of elasticity of substitution in housing production

marginal rate of substitution of the public output for the numeraire 